\title{
A formação acadêmica como fator potencializador da responsabilidade social do design
}

Higher education as enhancer of social responsibility in design

\section{Deborah Camila Viana Cardoso}

Universidade do Estado de Minas Gerais

deborahcvcardoso@gmail.com

Edson José Carpintero Rezende

Universidade do Estado de Minas Gerais

edson.carpintero@gmail.com

\section{Cláudia Fátima Campos}

Universidade do Estado de Minas Gerais

claudiacammpos@gmail.com

$\mathbf{X}$

\section{PROJËTICA}

\section{COMO CITAR ESTE ARTIGO:}

CARDOSO, Deborah Camila Viana; REZENDE, Edson José Carpintero; CAMPOS, Cláudia Fátima. A formação acadêmica como fator potencializador da responsabilidade social do design. Projética, Londrina, v. 12, n. 2, p. 189-214, 2021.

DOI: 10.5433/2236-2207.2021v12n2p189

Submissão: 17-04-2020

Aceite: 17-06-2020 
Projética, Londrina, v. 12, n. 2, p. 189-214, agosto 2021

RESUMO: Este trabalho tem o objetivo de demonstrar a necessidade da atuação socialmente responsável, tanto da universidade quanto dos cursos que a integram, com foco nos cursos superiores de design. Para tanto, utilizou-se como método a revisão da literatura. Constatou-se que os cursos de design podem direcionar seus currículos para obterem esta formação socialmente responsável, de forma que a atuação do profissional no mercado de trabalho seja reflexo do tipo de ensino que recebeu nos bancos acadêmicos.

Palavras-chave: Design. Usuário. Responsabilidade social. Educação.

ABSTRACT: This work aims to demonstrate the need for a socially responsible performance - from the university and also from the major degrees provided by it, mainly on higher education Design courses. To do so, the literature review method was used. The conclusions of this study were that design courses can direct their curricula to achieve a socially responsible education, so that the professional's performance in the labor market could reflect the education received at the university.

Keywords: Design. User. Social responsibility. Education.

\section{INTRODUÇÃO}

No cenário atual, no qual os problemas sociais são eminentes, o design tem sido reconhecido como área ou disciplina importante na configuração de soluções para problemas de variadas ordens, na prestação de serviços e no desenvolvimento de produtos. Por meio do design é possível contribuir para: a resolução de alguns problemas sociais, a implementação de políticas públicas a valorização de culturas e de realidades sociais ao se trabalhar a essência dos serviços e produtos projetáveis, resultando em significado para aquele público usuário, cuja centralidade no processo projetual é imprescindível. 
As universidades e os cursos de design, portanto, têm papel preponderante nesse cenário. As primeiras, porque, agindo com responsabilidade social universitária, não podem deixar seus currículos distantes da realidade social que as cercam. Uma das críticas que as universidades recebem é de serem ilhas de conhecimento desconectadas da vida prática e distantes das reais necessidades da população, à qual deveriam de alguma forma servir. Como consequência da responsabilidade social universitária, os cursos de design, especificamente, não podem se portar de forma alheia aos problemas da sociedade que os cerca, devendo também seus currículos proporcionar a flexibilidade necessária para que possam responder aos anseios sociais utilizando o conhecimento projetual que desenvolvem com os alunos como ferramenta para isso.

Outro diferencial que os cursos de design podem oferecer aos alunos, futuros designers, é a demonstração de sua capacidade de impactar a vida das pessoas ao sempre considerar o ser humano, o usuário, como peça central de projetos, sendo seu objetivo primordial a resposta às suas demandas. O aluno deve compreender, durante sua formação, que ele pode impactar a realidade que 0 cerca por meio de ações projetuais direcionadas para o bem-estar coletivo, dentro do mercado de trabalho, agindo com responsabilidade social e ética.

Essa pesquisa tem, portanto, o objetivo de demonstrar a necessidade da efetivação da responsabilidade social universitária para promover uma adequada formação do graduado em design para que atue de modo socialmente responsável e ético no mercado de trabalho; para que considere a relevância do usuário, bem como suas demandas, e também os problemas proeminentes na sociedade em que atuará profissionalmente. Para tanto, o método utilizado foi o da revisão da literatura, sistematizando pontos de vista de autores a respeito do tema em questão neste estudo. 
Projética, Londrina, v. 12, n. 2, p. 189-214, agosto 2021

\section{A RESPONSABILIDADE SOCIAL UNIVERSITÁRIA E OS IMPACTOS SOCIAIS DECORRENTES DELA}

Ribeiro e Magalhães (2014) e Silva (2015) afirmam que a Responsabilidade Social Universitária (RSU) surge cronologicamente em seguida da Responsabilidade Social Corporativa'. O contexto social é o de globalização, no qual, com a adoção de modelos político-econômicos que pregavam o Estado mínimo, ou seja, a mínima intervenção do Estado na economia e na promoção do bem-estar social, transmitiuse para as organizações da sociedade civil a responsabilidade sobre essas ações. As pressões de entidades externas, estrangeiras, como o Banco Mundial, também favoreceram essa diminuição de intervenção estatal nesse tipo de política. A ideia de RSU veio, então, com a mesma lógica da responsabilidade social corporativa, ou seja, que as instituições de nível superior deveriam fazer algo além de sua tarefa básica, observando os impactos dessas ações sobre elas mesmas e sobre as pessoas que se relacionam com ela (stakeholders²). Silva (2015) salienta que a RSU surge, dentro de um contexto de complexidade, mas que, por meio dela, a universidade poderá lutar contra a realidade de isolamento em que vive, como se os problemas ambientais e sociais só dissessem respeito à comunidade e não à universidade.

[1] A história da responsabilidade social corporativa foi popularizada dos anos 1950 a 1970, com a emergência da ideia de que corporações têm outras obrigações diretamente relacionadas à sociedade, em geral, que não apenas aquelas que envolvem somente seu público consumidor definem, portanto, a responsabilidade social corporativa como "a extensão do papel empresarial além de seus objetivos econômicos". Souza (2007, p. 69) afirma que "a disseminação do conceito de responsabilidade social no entorno social empresarial permite criar uma nova postura da empresa, incorporando as demandas sociais diretamente na gestão e, consequentemente, em atividades regulares como produção, distribuição, recursos humanos e, sobretudo, no âmbito do projeto e, particularmente, na esfera do design".

[2] Exemplos de stakeholders nesse caso são: "ex-discentes, discentes, docentes, comunidade, comunidade empresarial, famílias, agências de fomento, governo" (RIBEIRO; MAGALHÃES, 2014, p. 143). 
A formação acadêmica como... design CARDOSO, D. C. V.; REZENDE, E. J. C.; CAMPOS, C. F.

No contexto universitário, Santos Filho (2013, p. 3) afirma que a responsabilidade social universitária está ligada à missão da universidade, que tem sido descrita por muitas instituições como "promover a aprendizagem através da descoberta (pesquisa), transmissão (ensino) e aplicação do conhecimento (serviço)".

Ribeiro e Magalhães (2014), no entanto, afirmam que há uma necessidade imperiosa de se enxergar essa missão como algo mais abrangente que isso, pois, se assim não for, o ensino superior estará sendo encarado não como uma forma de emancipação humana, mas como uma forma de criar capital humano. As autoras afirmam, então, que por mais que as universidades, principalmente as privadas, tentem agir com a lógica do modelo mercantil, que cria um mercado de ensino, no qual os alunos são clientes-consumidores, deve-se pensar que a educação produzida nas universidades, públicas ou particulares, será sempre um bem público, no sentido de que promoverá ações e consequências na sociedade que a abriga. Logo, a universidade que tem seu modelo de gestão baseado em Responsabilidade Social Universitária buscará agir como um elo entre a sociedade, com seus problemas locais e globais, e o conhecimento gerado em seu interior, de forma que este seja aplicado na resolução de problemas daquela. Silva (2015) afirma que esse tipo de raciocínio, que trata a educação superior como algo capaz de produzir conhecimento economicamente útil é uma simplificação de pensamento, causada por essa lógica mercantilista do mercado educacional.

Silva (2015, p. 9 - grifo nosso) conceitua a RSU como aquilo que diz respeito à "gestão ética dos processos de ensino, pesquisa, extensão e administração institucional" e que, por ser uma categoria em construção, convida a universidade a se posicionar de forma coerente, relacionando a missão da universidade, a identidade, a cultura de cada Instituição de Ensino Superior (IES) e seu dever social de responder a demandas da sociedade. A autora acrescenta, em consonância com Ribeiro e Magalhães (2014), que a missão da universidade é também a de formar cidadãos com as características necessárias ao desenvolvimento e à construção de 
Projética, Londrina, v. 12, n. 2, p. 189-214, agosto 2021

uma sociedade mais democrática e próspera, indo além da tradicional produção, reprodução e divulgação de conhecimento. A universidade que atua com RSU "atua em todos os aspectos da vida social, sem perder seu caráter acadêmico" (SILVA, 2015, p. 13), ou seja:

\begin{abstract}
Requer-se hoje, da universidade: não só a formação profissional tecnicamente qualificada, mas também uma educação que prepare o/a estudante para o pleno exercício da cidadania; não só a produção do conhecimento científico e tecnológico, mas também que a sua atividade de pesquisa esteja voltada para a resolução de problemas e para a resposta às demandas da comunidade e que esteja alinhada com um modelo de desenvolvimento que privilegie, além do crescimento da economia, a promoção da qualidade de vida (RIBEIRO; MAGALHÃES, 2014, p. 138).
\end{abstract}

Para Ribeiro e Magalhães (2014), a RSU tem quatro dimensões: uma de desenvolvimento social; outra de desenvolvimento cultural; uma terceira de desenvolvimento sustentável e, por fim, a de desenvolvimento econômico. Portanto, para atender a todas essas dimensões, os temas relacionados à Responsabilidade Social Universitária diriam respeito à democracia e à transparência, às boas condições de trabalho e salários equitativos, ao meio ambiente, à educação socialmente responsável, incluindo a gestão social dos conhecimentos e à alocação da extensão como parte da matriz curricular ${ }^{3}$ para melhorar a formação dos alunos e a promoção do desenvolvimento social local e regional (SILVA, 2015).

Santos Filho (2013) afirma que há três concepções de pensamento distintas em relação ao cumprimento da missão universitária: a primeira delas é a vertente idealista, tradicionalista ou liberal conservadora, que determina que o objetivo da universidade é promover a busca do saber por si mesmo, ou seja, sem engajamento social. Pensamento que, para o autor, não tem guarida no mundo moderno, pois ciência e tecnologia se transformaram na "nova riqueza das nações".

[3] O que já está presente no Plano Nacional de Educação (PNE), desde 2014, como a garantia de, "no mínimo, $10 \%$ do total de créditos curriculares exigidos para a graduação em programas e projetos de extensão universitária, orientando sua ação, prioritariamente, para áreas de grande pertinência social (BRASIL, 2014). 
Requer-se hoje, da universidade: não só a formação profissionaltecnicamente qualificada, mas também uma educação que prepare o/a estudante para o pleno exercício da cidadania; não só a produção do conhecimento cientifico e tecnológico, mas também que a sua atividade de pesquisa esteja voltada para a resolução de problemas e para a resposta às demandas da comunidade e que esteja alinhada com um modelo de desenvolvimento que privilegie, além do crescimento da economia, a promoção da qualidade de vida.

(RIBEIRO; MAGALHÃES, 2014, p. 138)

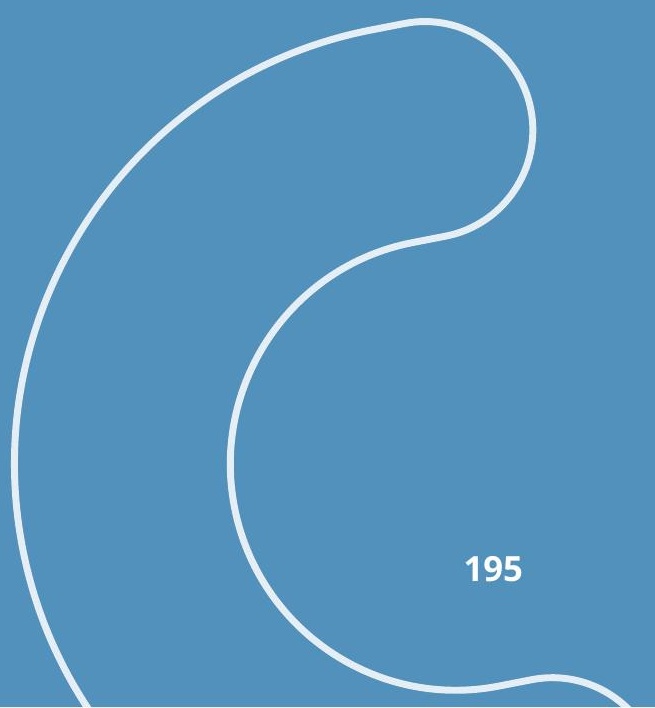


Projética, Londrina, v. 12, n. 2, p. 189-214, agosto 2021

A segunda vertente é a dos ativistas ou críticos radicais. Nessa visão, a universidade deveria se engajar na solução dos problemas sociais e do Estado, mas sem renunciar à crítica às instituições do governo e da sociedade civil.

Essa corrente de pensamento teve sua origem nos anos 1960, quando estudantes, professores e intelectuais de "esquerda" passaram a criticar a posição da universidade funcionalizada, ou seja, que trabalhasse para atender a todas as demandas do governo e da sociedade, principalmente as relacionadas a guerras, sem nenhuma crítica a respeito do fato (SANTOS FILHO, 2013).

A terceira corrente de pensamento é a funcionalista, que defende um intervencionismo moderado e reformista, que pretendia responder a todas as demandas da sociedade e do Estado, pois acreditava que a universidade é o celeiro de conhecimento e deve trabalhar em prol de todos e da melhoria da qualidade de vida das pessoas. O problema apontado por Santos Filho (2013) a esse tipo de pensamento é que, além de burocratizar a instituição por aumentar o tamanho da máquina administrativa da universidade, ela perde sua autonomia e passaria a não mais estabelecer seus objetivos intelectuais e pedagógicos, mas apenas a responder demandas externas.

Do início do século XX até os dias atuais, devido a essa variedade de interpretações a respeito das funções e de sua missão, a universidade passou a se encontrar no seio de inúmeras tensões econômicas, sociais e governamentais. Por esse motivo, essas instituições de ensino superior passaram por diversas crises. A primeira delas foi a crise da hegemonia, caracterizada pela incapacidade de a universidade desempenhar suas funções essenciais. Em seguida, a crise da legitimidade, advinda da contradição entre hierarquização e democratização das instituições, derivada da "falência dos objetivos coletivamente assumidos ou esperados". Por fim, a crise institucional, que está relacionada à autonomia institucional e à produtividade social, ou seja, quando se pretende impor modelos 
vigentes em outras instituições às universidades. Para resolver essas crises, a universidade deve repensar suas funções em relação à sua responsabilidade social (SANTOS FILHO, 2013).

Nunes, Pereira e Pinho. (2017, p. 167) afirmam que essa crise da universidade está diretamente relacionada ao fato da pressão que a universidade sofre por agir com RSU. As autoras defendem a tese de que a autonomia universitária foi instituída pela Constituição da República de 1988 ao determinar no art. 207 a autonomia didático-científica, administrativa, financeira e patrimonial das universidades, obedecendo ao princípio da indissociabilidade entre ensino, pesquisa e extensão. Para as autoras, isso "evidencia a questão central relacionada ao conceito de responsabilidade social aplicado às instituições educacionais", uma vez que somente há universidade quando há formação em graduação e pósgraduação com indissociabilidade entre esses pilares e que, conforme a LDB/1996 em seu art. 52 determina, as universidades caracterizam-se pela:

\section{Art. $52[\ldots]$}

I - produção intelectual institucionalizada mediante o estudo sistemático dos temas mais relevantes, tanto do ponto de vista científico e cultural, quanto regional e nacional. [...] (BRASIL, 1996)

Portanto, é impossível que a universidade se estabeleça sem que os problemas sociais mais relevantes possam ser estudados no bojo de seu ensino, pesquisa e extensão. Nunes, Pereira e Pinho. (2017) afirmam, porém, que essa autonomia é relativa, pois as universidades estão vinculadas ou são reguladas por órgãos governamentais, que dificultam a realização de sua missão. Logo, seria contraditório falar em RSU quando a universidade não tem a real autonomia para ação, o que, para elas, culminou nas crises anunciadas por Santos Filho (2013), acima citadas, de hegemonia, legitimidade e a institucional.

Em consonância com todo o estudado, portanto, Santos Filho (2013) aponta que, para que a universidade cumpra sua responsabilidade social, 
Projética, Londrina, v. 12, n. 2, p. 189-214, agosto 2021

deveria, no âmbito da pesquisa, valorizar a pesquisa aplicada para soluções de problemas relacionados à realidade brasileira e ao mundo real. Deve também engajar os envolvidos com os problemas estudados pela universidade na solução deles e cita a metodologia da pesquisa-ação como uma das formas de se fazer isso. Em relação à extensão, afirma que a universidade deve sim prestar serviços especializados às comunidades e Estado, no sentido de promover o aprendizado dos alunos e a emancipação daqueles que utilizam tal serviço. Em relação ao ensino, o autor afirma que as universidades, para cumprir seu papel, devem se esforçar para aproximar o currículo da graduação dos problemas da sociedade brasileira, ou seja, integrar o currículo da universidade à realidade contemporânea. Para isso, reformas curriculares devem ser propostas de forma a promoverem maior interdisciplinaridade ${ }^{4}$ do ensino na graduação e adequarem a metodologia de ensino-aprendizagem a essa nova realidade pedagógica de engajamento. O autor sugere que sejam adotadas: a aprendizagem baseada em problemas; a aprendizagem baseada em serviço; a pedagogia cooperativa, que incentiva o trabalho em equipes e a cooperação entre as pessoas; que a avaliação do estudante também esteja vinculada às atividades desenvolvidas na aprendizagem baseada em serviço. Por fim, destaca a necessidade de uma política de valorização do corpo docente das instituições, para que eles se sintam constantemente estimulados a realizarem suas funções da melhor forma possível, com programas de melhorias de salários, estímulos financeiros à pesquisa aplicada e à promoção da estabilidade dos professores.

[4] Pires (1998) apresenta a distinção entre os termos multidisciplinaridade, interdisciplinaridade e transdisciplinaridade. Quando se fala em multidisciplinaridade, compreende-se que há uma justaposição de disciplinas, ou seja, que há uma tentativa de trabalho em conjunto, mas que cada professor aborda o tema sob sua própria ótica, o que fez com que não haja, de fato, interação entre as disciplinas. Para a autora, as "pessoas estudam perto, mas não juntas" (p. 176). A interdisciplinaridade já considera um diálogo entre as disciplinas e é um caminho para se superar a superespecialização e a desarticulação entre saberes, teoria e prática. Ela é uma forma de se chegar à transdisciplinaridade que, conforme Menezes (2001), representa a busca de um novo paradigma para a educação, com o fim das fronteiras entre as disciplinas e com o saber organizado de forma holística, criando, na verdade, novos campos do conhecimento. 
A formação acadêmica como... design

\section{A RESPONSABILIDADE SOCIAL DO DESIGN: OS REQUISITOS SIMBÓLICOS DO PROJETO E A CONSIDERAÇÃO DA REALIDADE SOCIAL DOS USUÁRIOS}

Em relação aos cursos de design, principalmente quando inseridos no âmbito de universidades, pode-se aplicar um raciocínio análogo ao aplicado à responsabilidade social universitária: devem-se observar como são organizados os currículos para que a interdisciplinaridade ocorra e para que as disciplinas não se mostrem isoladas e alheias aos problemas sociais. É fundamental que o ensino, pesquisa e extensão sejam focados também em problemas reais. E, para isso, devem ser aplicados métodos adequados para enfrentar esses desafios, de forma a promover melhorias na comunidade que cerca a universidade e no aprendizado dos próprios alunos (SANTOS FILHO, 2013). Por meio desta prerrogativa, os alunos poderiam desenvolver melhor as habilidades necessárias ao exercício profissional ainda dentro da universidade (BRASIL, 1996). Isso promoveria um maior engajamento dos alunos e professores com o curso e a instituição de ensino que puder proporcionar essa experiência (SANTOS; SOUZA, 2013). Os currículos devem ser pensados de forma a permitir essa flexibilização em relação às novas demandas que surgirem no mercado e na sociedade, conforme determinam as diretrizes curriculares nacionais (DCN) para o ensino do design (BRASIL, 2004).

A Lei de Diretrizes e Bases de 1996 especifica as finalidades da educação superior em seu art. 43, descrito a seguir, deixando clara a necessidade de integração entre universidade e sociedade, de forma que os problemas atuais da sociedade sejam estudados de maneira a estimular, no seio da universidade, a reflexão sobre os mesmos e a busca de soluções que beneficiam todas as partes envolvidas:

Art. 43. A educação superior tem por finalidade:

I - estimular a criação cultural e o desenvolvimento do espírito científico e do pensamento reflexivo;

II - formar diplomados nas diferentes áreas do conhecimento, aptos para a inserção em setores profissionais e para a participação no desenvolvimento da sociedade brasileira, e colaborar na sua formação contínua.

III - incentivar o trabalho de pesquisa e investigação científica, visando o desenvolvimento da ciência e da tecnologia e da criação e difusão da cultura, e, desse modo desenvolver o entendimento do homem e do meio em que vive; 
Projética, Londrina, v. 12, n. 2, p. 189-214, agosto 2021

IV - promover a divulgação de conhecimentos culturais, científicos e técnicos que constituem patrimônio da humanidade e comunicar o saber através do ensino, de publicações ou de outras formas de comunicação;

V - suscitar o desejo permanente de aperfeiçoamento cultural e profissional e possibilitar a correspondente concretização, integrando os conhecimentos que vão sendo adquiridos numa estrutura intelectual sistematizadora do conhecimento de cada geração;

$\mathrm{VI}$ - estimular o conhecimento dos problemas do mundo presente, em particular os nacionais e regionais, prestar serviços especializados à comunidade e estabelecer com esta uma relação de reciprocidade;

VII - promover a extensão, aberta à participação da população, visando à difusão das conquistas e benefícios resultantes da criação cultural e da pesquisa científica geradas na instituição (BRASIL, 1996 - grifo nosso).

De acordo com a Resolução CNE/CES 5/2004, que estabeleceu as diretrizes curriculares para os cursos superiores em design no Brasil (BRASIL, 2004), são os projetos pedagógicos dos cursos de design de cada IES que devem estabelecer sua concepção e suas peculiaridades, com base no perfil da região geográfica em que estão inseridos. Além disso, é também o projeto pedagógico de cada IES que deve descrever sua organização curricular e o perfil desejado de formando, de maneira que, ao final do curso, ele seja capaz de desenvolver "projetos que respeitem e atendam às comunidades e usuários a que se destinem, no aspecto estético, artístico, tecnológico e cultural" - arts. $2^{\circ}$ a $5^{\circ}$ da Resolução CNE/CES 5/2004, grifo nosso. Um egresso, portanto, que aja com reverência às comunidades e aos usuários é o que se deseja, independente de onde o curso de design seja instalado e de como seja organizado.

Observa-se, então, que a atuação profissional do designer cada vez mais está relacionada à responsabilidade social. Manzini $(2006,2008)$ afirma que o design pode contribuir de forma significativa para a melhoria da qualidade de vida das comunidades, à medida que direciona sua atividade para encontrar soluções sustentáveis para (design for) e com (design in) as pessoas envolvidas e interessadas na resolução de problemas específicos, o que estaria ligado diretamente à ideia de inovação e tecnologia social. Esse bem-estar está diretamente relacionado não aos produtos materiais que se consome, mas aos serviços, às experiências e 
A formação acadêmica como... design

CARDOSO, D. C. V.; REZENDE, E. J. C.; CAMPOS, C. F.

aos produtos intangíveis que, em longo prazo, possam oferecer aos moradores melhores condições de vida. No mesmo sentido, Moraes (2009) afirma que:

[...] vários atributos antes tidos como secundários, por exemplo, o "valor de estima", os "fatores emotivos, estéticos e psicológicos", a "qualidade percebida", a "certificação de origem" e o "conceito de terroir" (como reconhecimento da comunidade e do território onde se produz), são hoje fatores determinantes e diferenciais competitivos alçados à condição de atributos primários. Os atributos tecnicistas até então predominantes eram lógicas pretensiosamente determinantes e lineares portadores de soluções preestabelecidas que definiam o produto e a produção na era moderna, ao mesmo tempo que buscavam suprir, de maneira uniforme, a grande massa consumidora humana (MORAES, 2009, p. 10).

Souza (2007), em discurso consonante com Manzini $(2006,2008)$ e Moraes (2009), afirma que a implementação de projetos de design gera, em maior ou menor escala, a transformação no entorno social. Se antes, a satisfação do usuário ao receber o resultado do processo de design estava focada nas qualidades instrumentais, utilitárias ou formais de um artefato, hoje ela está muito mais centrada nas qualidades simbólicas, rituais, relativas ao status que esse produto proporciona. E que cabe ao designer mudar a abordagem tradicional do design, enquanto produtor de objetos, para uma abordagem sistêmica, na qual a atividade é vista como reguladora de processos dinâmicos de mudança de sistemas, estes não entendidos sob o ponto de vista unicamente material, mas também imaterial.

O design sistêmico seria um novo modelo de design, adequado para atender demandas igualmente novas, que versam sobre questões ambientais, tecnológicas, econômicas, sociais e culturais. O designer deve rever seus valores no momento da projetação, e os projetos devem ser conduzidos de forma que se atinja o nível de satisfação dos usuários ${ }^{5}$, mas que respeite os valores ético-sociais, culturais, econômicos e ambientais da comunidade em que se está inserido (DZIOBCZENSKI et. al., 2011; MANZINI, 2008).

[5] Para Souza (2007), o designer trabalha em lacunas de necessidades, individuais e sociais, e sua ação projetual sempre está relacionada a uma intenção, que é suprir essas demandas em busca do bem-estar, entendido de forma ampla, do usuário. 
[...] vários atributos antes tidos como secundários, por exemplo, o "valor de estima", os "fatores emotivos, estéticos e psicológicos", a "qualidade percebida", a "certificação de origem" e o "conceito de terroir" (como reconhecimento da comunidade e do território onde se produz), são hoje fatores determinantes e diferenciais competitivos alçados à condição de atributos primários. Os atributos tecnicistas até então predominantes eram lógicas pretensiosamente determinantes $e$ lineares portadores de soluções preestabelecidas que definiam o produto e a produção na era moderna, ao mesmo tempo que buscavam suprir, de maneira uniforme, a grande massa consumidora humana (MORAES, 2009, p 10).

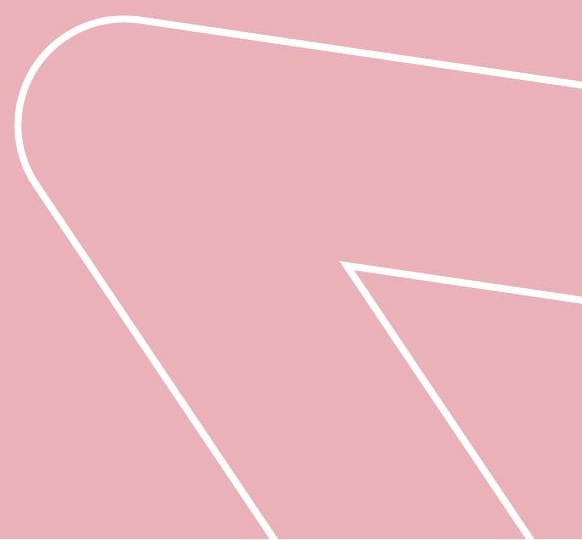


Bonsiepe (2012), no mesmo sentido, ao falar sobre os efeitos da crise econômica sobre o design, afirma que o design tanto é atingido pela crise, quanto tem atuação sobre ela. Ele é atingido, uma vez que os sistemas econômicos tiveram seu curso mudado: está havendo um deslocamento do capitalismo produtivo, alinhado com a produção industrial, para um capitalismo financeiro, que atua na manipulação de valores simbólicos e virtuais, ou seja, está havendo uma mudança fundamental do real para o virtual, que tem impactos sobre o design e a forma pela qual ele se desenvolve atualmente. O design também atua sobre a crise, uma vez que não há como negar o impacto de atividades projetuais sobre a realidade prática e sobre a sociedade, mas o autor não tem a presunção de afirmar que o design, por si só, pode acabar com a crise.

Bonsiepe (2012), no entanto, trata dos problemas que a falta de uma teoria do design acarreta, ou seja, a falta de uma orientação teórico-filosófica da área faz com que o nível de maturidade e os discursos do design se caracterizem por um baixo grau de elaboração, se comparados a outras áreas do conhecimento, e que seu status cognitivo esteja bastante limitado a um domínio de visualidade. Isso também favoreceu a crise do design que ocorreu a partir da década de 1990, quando o termo design foi associado de forma reduzida a aspectos estético-formais, ao efêmero, ao caro, ao supérfluo e ao pouco prático. Ideia esta que foi difundida pela mídia, mas que não corresponde à realidade, pois design, para o autor, é essência. Ele está na essência das coisas, e não naquilo que se pode agregar. Ao contrário da arte que, para o autor, tem a função de não ter função, “o design tem a função imprescindível de integrar ciências e tecnologias na vida cotidiana de uma sociedade, concentrando-se na zona intermediária entre produto e usuário. [...] Pode contribuir para [...] fazer mais habitável o mundo dos artefatos materiais e simbólicos" (BONSIEPE, 2012, p. 7). Ao fazer um paralelo entre a interpretação de textos e a interpretação do design, o autor formula algumas questões que deveriam ser respondidas para que os resultados de ações de design tenham de fato efeitos sociais representativos: "1 - Para quem esse design foi feito? 2 - Em quais circunstâncias (econômicas, sociais e tecnológicas)?" (BONSIEPE, 2012, p. 5).

Desta maneira, o autor dá alguns exemplos de formas de atuação do design na sociedade bastante relevantes ao nosso tempo: a crise energética, que 
Projética, Londrina, v. 12, n. 2, p. 189-214, agosto 2021

exige ações relevantes de design no sentido de desenvolver produtos que gastem pouca energia ao serem fabricados, ao serem consumidos e no pós-consumo; a questão do desemprego, uma vez que problemas sociais podem ser resolvidos com atividades projetuais de alcance social; a questão da exportação de commodities, às quais ficam restritas aos países subdesenvolvidos, e a dúvida de que se o design desenvolvido localmente (o que não se confunde com arte ou artesanato) pode contribuir para a autonomia local (BONSIEPE, 2012).

Latour (2014, p. 4), apesar de não fornecer uma definição fechada do que, para ele, seria design, aponta cinco de suas características, as quais ele denomina as "cinco vantagens do conceito de design". A primeira delas é a modéstia que o termo carrega. Há certa humildade/modéstia em dizer que se pode construir algo com design, mas pode-se, na verdade, reelaborar todas as coisas da existência através do design, pois o ato projetual tem um longo alcance. A segunda vantagem do termo: design é atenção cuidadosa aos detalhes e está comumente associado aos termos: habilidade, arte, perícia. Essas características, antes, eram vistas como entrave à rápida marcha do progresso, uma vez que exigiam um modus faciendi um pouco mais demorado, com mais calma, para que ficasse bem realizado. Esse fazer cuidadoso, porém, ganhou outra conotação, menos pejorativa e mais valorizada pelo cuidado na execução. A terceira característica citada por Latour (2014) são as habilidades semióticas do design. Ao analisar o design de um artefato, estamos lidando com significados: comerciais, simbólicos, etc. O design é feito para ser interpretado na linguagem dos signos. Em francês: "dessein"; em italiano: "designo". Ele traz sempre consigo uma intenção, que infiltra nos produtos da atividade do designer e tem mais valor que o objeto em si. A quarta vantagem é o fato de que o design não é um processo que começa do zero: ele é sempre um redesign. 0 problema e a demanda sempre existem primeiro. O design é tarefa subsequente que visa melhorar uma realidade que já está posta. Por fim, a quinta e última característica, é o termo design estar ligado a uma dimensão ética, ou seja, por estar inserido em um contexto social, o design não pode se esquivar das questões de ordem moral e ética. 
Portanto, Latour (2014, p. 11) aponta que o design faz parte de uma revolução, motivada pela questão ecológica, que se tornou desafio de desenvolvimento das nações. O design tem, no entanto, características contrárias àquelas que se costuma ver em uma revolução, que são "modéstia, cuidado, precaução, habilidade, significado, atenção aos detalhes, conservação cuidadosa, redesign".

Manzini (1992) afirma que discussões a respeito dos valores da sociedade industrial e consumo em massa não poderiam mais ser evitadas, tendo em vista o surgimento de problemas ambientais mundiais, e que isso traria para a sociedade, e para o design, uma transformação em suas práticas de projeto, produção e consumo. O problema ambiental de que trata o autor, não é apenas o relacionado ao limite físico da biosfera, mas também o limite do ambiente que ele denomina semiótico, ou seja, as pessoas não estão conseguindo lidar com a quantidade enorme de números e signos que se transformam e que devem interpretar a todo momento. Por isso, além de novos modelos de produção e consumo serem avaliados do ponto de vista material, o autor afirma que um novo paradigma relacionado à estabilidade de identidades culturais também está sendo reorganizado, com a finalidade da permanência. Desta maneira, novos valores e concepções mais profundas de qualidade de produtos e sistemas emergiriam dessa mudança de paradigma. Assim, a responsabilidade do designer nesse contexto seria contribuir para a construção de um mundo mais habitável, no qual "os seres humanos não apenas sobreviveriam, mas também expressariam e expandiriam suas possibilidades culturais e espirituais" (MANZINI, 1992, p. 6). Portanto, para o autor, uma mudança deste tipo, que abordasse aspectos de consumo, produção em massa, limites ambientais físicos da biosfera e do ambiente simbólico, apenas seria possível se aliada a uma forte transformação na cultura social; uma cultura que considere a complexidade dos sistemas e que encare suas limitações, buscando o equilíbrio no ambiente artificial em que se vive, de maneira ética.

Sobre essa questão, Manzini $(1992,2006,2008)$ aborda a questão da ética na atuação do designer nesse contexto de complexidade e ressalta a lacuna que existe na definição de uma "ética do design". O autor, porém, afirma que essa ética deve levar em consideração valores relativos, construídos sobre os princípios da responsabilidade e da solidariedade, e que o designer deve tentar conciliar o contexto social de produção em massa imposto pela sociedade regida pelos 
Projética, Londrina, v. 12, n. 2, p. 189-214, agosto 2021

valores da ciência e da tecnologia, com valores que dêem suporte à qualidade de vida buscada pelos usuários dos serviços de design em busca de um bem-estar mais sustentável, ligado intimamente à redução do consumo.

Santos (2013), sobre a atuação do designer na produção industrial, agindo de forma socialmente responsável, afirma que, em uma evolução de conceitos que envolvem a mudança de cultura do usuário/consumidor, o design começaria a atuar em níveis progressivos de ação na produção, desde a melhoria ambiental de fluxos, passando pelo redesign ambiental do mesmo produto, até a associação de um serviço ao produto, retirando dele o valor puramente material, e agregando a ele um valor subjetivo, emocional, imaterial, até essa evolução culminar no retorno do consumo ao nível de suficiência, e não mais ao de desejo, como acontece hoje. Santos (2013, p. 14) denomina esse movimento como“processo evolucionário do consumo sustentável", causado pela maturidade do design e sua trilha em direção à melhoria ambiental (figura 1), o que Manzini e Meroni (2009, p. 14) chamam de "transição do design em direção à sustentabilidade", ao abordar também a questão da sustentabilidade e a necessidade de mudança de estilo de vida das pessoas no sentido de diminuírem o impacto ambiental.

Figura 1 - Processo evolucionário em direção ao consumo sustentável.

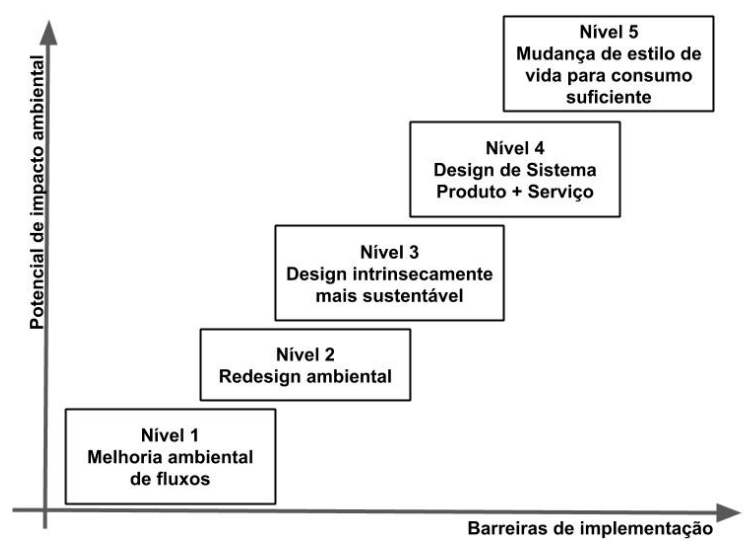

Fonte: Santos (2013, p. 14). 
Jonas (2006) afirma que não é necessária uma ética especial para o design, mas o que é necessário é um entendimento mais apropriado de planejamento: agir ao invés de fazer; planejar ações, ao invés de produtos. E que os objetivos éticos do design devem buscar a qualidade de vida em uma escala global. O autor afirma que, se perguntas certas fossem feitas, não faltariam ótimos designers para oferecer as respostas corretas, mas, para que essas perguntas corretas possam ser feitas, é necessária a interrupção do ciclo produtivo no qual o designer está inserido, para que ele pudesse refletir sobre sua posição para passar a exercer influência sobre a própria definição dos problemas, o que, de fato, trará possibilidades de alteração do futuro. A Figura 2 exemplifica esse processo, que significa uma mudança na posição do designer, que deixa de agir apenas no final da cadeia, mas passa a ser figura que influencia a sociedade em seus valores e problemas, com a finalidade de uma transformação futura positiva.

Figura 2 - Design e sua influência social com base na ética.

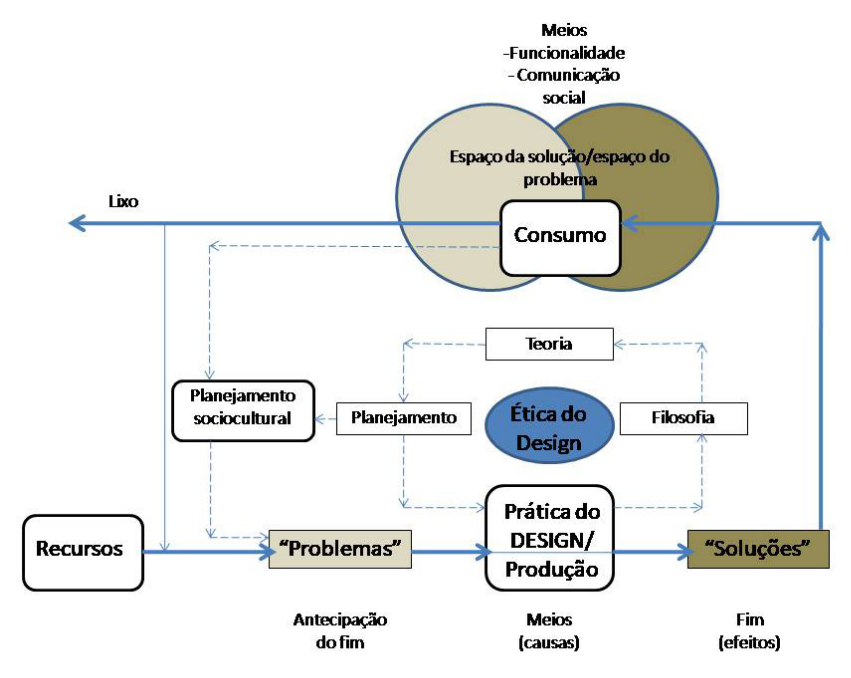

Fonte: Jonas (2006, p. 8 - tradução dos autores) 
Projética, Londrina, v. 12, n. 2, p. 189-214, agosto 2021

Souza (2007) afirma que o design pode proporcionar uma atuação socialmente responsável de maneira ampla, uma vez que se caracteriza por ser uma área que facilita a integração entre saberes científicos e necessidades sociais. O profissional de design, ao agir de forma socialmente responsável, pode contribuir com a otimização de recursos, com a diminuição de contrastes e com a viabilização de soluções originais de caráter social e cultural, desde o início da fase projetual até a implementação dos resultados, tanto em relação ao mercado, quanto em relação aos usuários. O autor também afirma que a aplicação de métodos de design em modelos gerenciais de empresas também contribui para esse tipo de gestão socialmente responsável, uma vez que o design tem, por premissa, uma atuação com foco no bem-estar do usuário, e não apenas no lucro, o que significa que estratégias e ações devem ser adaptadas para satisfazer as duas esferas de forma simultânea, sejam elas lucro e expectativas humanas. É o que autor chama de Design Socialmente Responsável (DSR - Design for Social Responsability), no qual empresas agem de forma competitiva, mas levam em consideração demandas sociais, como respeito ao meio ambiente, qualidade de vida, tecnologias limpas, etc.

Ono (2004), ao se deparar com a questão do design, da cultura e da identidade no contexto da globalização, afirma que a responsabilidade do designer é ainda maior nesse cenário social e econômico. A tendência que se verifica nesse movimento é a tentativa de homogeneização de valores, ideias e padrões sob o ponto de vista ocidental, norte-americano, primordialmente. Nesse sentido, a produção de bens em escala global também passou por alterações e vive entre a contradição de homogeneização e respeito às identidades e culturas locais. Portanto, o design, como responsável pela criação desses objetos, também se encontra em momento controverso, uma vez que, por mais que se busque homogeneidade, a riqueza cultural de cada povo reside na heterogeneidade de sua história e de sua relação com o objeto, que varia, indiscutivelmente, de lugar para lugar, de cultura para cultura.

Ou seja, um design para todos é diferente de um design homogêneo para todos, cabendo ao designer ter bom senso e considerar sempre o usuário final do 
serviço e seus anseios em relação àquele determinado objeto, de forma que suas expectativas pessoais sejam atingidas e sua vida melhorada de alguma forma a partir da execução de determinado projeto. Isso não exclui os produtos globais, mas não globaliza as culturas e identidades. Conclui Ono (2004) que a atenção dos designers deve ser despertada, portanto, para a "necessidade de se focalizar as pessoas ao longo de todo o processo de desenvolvimento de produtos" (ONO, 2004, p. 64), não podendo considerá-las estereótipos, apesar de ser essa a tendência globalizante da cultura.

\section{CONSIDERAÇÕES FINAIS}

A universidade que age com RSU busca a concretização de sua missão (pilares da universidade que são a promoção do ensino, da pesquisa e da extensão) de forma contextualizada e não-distanciada das realidades e demandas sociais que a cercam. Utilizam-se os problemas sociais para dar suporte aos pilares da universidade, promovendo-os de maneira a contribuir para melhoria da comunidade e oferecer resposta a seus anseios e problemas.

O design, inserido que está no contexto universitário, também não poderia se manter alheio aos problemas sociais e, agir com responsabilidade social e ética, nesse cenário, seria nada menos que considerar a realidade social de quem se projeta, os símbolos e valores envolvidos no projeto e o poder transformador que o design possui para projetar sistemas e planejar ações que impactam em micro e macrocosmos de usuários prioritariamente considerados como base de qualquer projeto de design.

A educação em design, dentro da universidade, portanto, pode direcionar o futuro profissional a agir com mais ou menos responsabilidade social no mercado de trabalho. O ensino que considere o humano e sua realidade sócio-cultural, em maior ou menor escala, como parte integrante de qualquer solução pensada em 
Projética, Londrina, v. 12, n. 2, p. 189-214, agosto 2021

projetos de design, ainda durante a formação do profissional na graduação, é indispensável para essa transformação.

Para que tudo isso seja possível, é essencial que os cursos superiores se atentem para a necessidade de reorganização de seus projetos pedagógicos e matrizes curriculares, de forma que permitam flexibilidade suficiente para abarcar esse tipo de ensino, baseado em problemas e situações reais e que a transdisciplinaridade seja uma meta constante, uma vez que disciplinas isoladas não conseguiriam, por si sós, oferecer respostas às demandas sociais cada vez mais complexas. Promover o ensino superior e o ensino do design tendo como meta a concretização do ensino, pesquisa e extensão de maneira indissociável e com foco nos problemas sociais de variadas ordens contribuiria sobremaneira para a melhoria local da comunidade e da relação entre ela e a universidade e entre ela e o design, que inclusive desceria do pedestal de serviço inatingível e caro para algo interessante e viável para todos.

O profissional de design quando não se atenta para a questão ética, sustentável e de mudanças de paradigmas sociais e que, sobretudo, não valoriza o usuário e as comunidades para quem projeta, não age com responsabilidade social e não explora as enormes possibilidades de atuação do design enquanto agente de transformação da realidade social. 
A formação acadêmica como... design

CARDOSO, D. C. V.; REZENDE, E. J. C.; CAMPOS, C. F.

\section{REFERÊNCIAS}

1. BONSIEPE, Gui. Design e crise. Agitprop, São Paulo, v. 4, n. 44, p. 1-11, 2012.

Disponível em: http://www.guibonsiepe.com/textos/archivos/2012_03_ Design-e-Crise_AGITPROP.pdf>. Acesso em: 11 mar. 2019.

2. BRASIL. Lei $n^{\circ} 9.394$, de 20 de dezembro de 1996. Estabelece as diretriz/s e bases da educação nacional. Brasília, DF: Presidência da República, 1996. Disponível em: https://www2.senado.leg.br/bdsf/bitstream/r/andle/ id/70320/65.pdf. Acesso em: 31 mar. 2018.

3. BRASIL. Ministério da Educação e Cultura. Resolução n 5, de 8 le março de 2004. Aprova as diretrizes curriculares nacionais do curso de graduação em design e dá outras providências. Brasília, DF: Conselho National de Educação, 2004. Disponível em: http://portal.mec.gov.br/cne/arqulyos/pdf/ rces05_04.pdf. Acesso em: 06 fev. 2018.

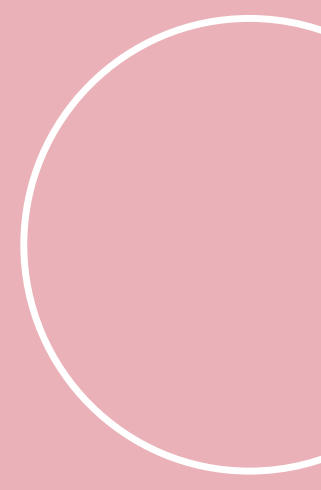

4. BRASIL. Lei $n^{\circ} \mathbf{1 3 . 0 0 5}$, de 25 de junho de 2014. Aprova o Plano Nacióal de Educação - PNE e dá outras providências. Brasília, DF: Presidência dâ República, 2014. Disponível em: http://www.planalto.gov.br/ccivil_03/_ ato2011-2014/2014/lei/l13005.htm. Acesso em: 06 abr. 2020.

5. DZIOBCZENSKI, Paulo Roberto Nicoletti et al. Inovação através do design: princípios sistêmicos do pensamento projetual. Design \& Tecnologia, Porto Alegre, v.3, n. 3, p. 54-63, 2011. Disponível em: https://www.researchgate. net/publication/304170151_Inovacao_Atraves_do_Design_Principios_ Sistemicos_do_Pensamento_Projetual. Acesso em: 06 abr. 2020.

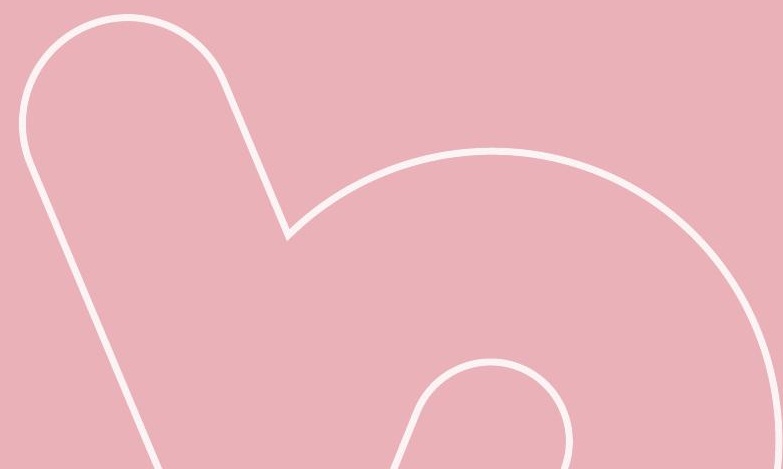


Projética, Londrina, v. 12, n. 2, p. 189-214, agosto 2021

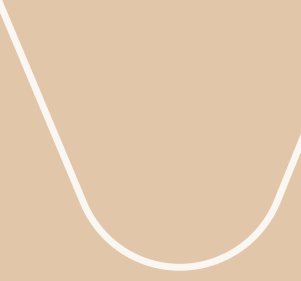

6. JONAS, Wolfgang. A special moral code for design? Design Philisophy Papers, [s. I.], v. 4, n. 2, p. 117-132, 2006. Disponível e m : h t t p : / / w w w. thestudio a t the ed ge of the world . com / uploads/4/7/4/0/47403357/04jonasspecial_moral_code_for_design.pdf. Acesso em: 03 mar. 2019.

7. LATOUR, Bruno. Um prometeu cauteloso? Alguns passos rumo a uma filosofia do design. Agitrop, São Paulo, v. 6, n. 58, p. 1-21, jul./ago. 2014. Disponível em: http://filosofiadodesign.com/wp-content/uploads/2014/10/ Prometeu-cauteloso.pdf. Acesso em: 12 mar. 2019.

8. MANZINI, Ezio. Prometheus of the everyday: the ecology of the artificial and the designer's responsability. Design Issues, Londres, v. 9, n. 1, p. 5-20, 1992. Disponivel em: https://www.jstor.org/stable/1511595?readnow=1\&seq=1\#page_scan_tab_contents. Acesso em: 03 mar. 2019.

9. MANZINI, Ezio. Design, ethics and sustainability: guidelines for a transition phase. In: SOTAMAA, Yrjö et al. Cumulus working papers Nantes. Helsinki: University of Art and Design Helsinki, p. 9-15, 2006. Disponível em: https://www.cumulusassociation.org/wp-content/uploads/2015/09/WP_ Nantes-16_06.pdf. Acesso em: 06 abr. 2020.

10. MANZINI, Ezio. Design para inovação social e sustentabilidade: comunidades criativas, organizações colaborativas e novas redes projetuais. Rio de Janeiro: E-papers, 2008.

11. MANZINI, Ezio; MERONI, Anna. Design em transformação. In: Krucken, Lia. Design e território: valorização de identidades e produtos locais. São Paulo: Studio Nobel, 2009, p. 13-16.

12. MENEZES, Ebenezer Takuno de; SANTOS, Thais Helena dos. Verbete transdiciplinaridade. Dicionário interativo da educação brasileira Educabrasil. São Paulo: Midiamix, 2001. Disponível em: http://www. educabrasil.com.br/transdisciplinaridade/. Acesso em: 19 fev. 2019. 
13. MORAES, Dijon de. O papel atual do design. In: Krucken, Lia. Design e território: valorização, de identidades e produtos locais. São Paulo: Studio Nobel, 2009, p. 9-12.

14. NUNES, Enedina Betânia Leite de Lucena Pires; PEREIRA, Isabel Cristina Auler; PINHO, Maria José de. A responsabilidade social universitária e a avaliação institucional: reflexões iniciais. Avaliação, Campinas, v. 22, n. 1, p. 165-177, 2017. Disponível em: http://www.scielo.br/pdf/aval/v22n1/19825765-aval-22-01-00165.pdf. Acesso em: 12 abr. 2019.

15. ONO, Maristela Misuko. Design, cultura e identidade, no contexto da globalização. Revista Design em foco, Salvador, v. 1, n. 1, p. 53-66, jul./dez. 2004. Disponível em: https://silo.tips/queue/revista-design-em-foco-issnuniversidade-do-estado-da-bahia-brasil-5?\&queue_id=-1\&v=1617054029\&u =MTg5LjkwLjY2Ljc=. Acesso em: 19 mar. 2019.

16. PIRES, Marília Freitas de Campos. Multidisciplinaridade, interdisciplinaridade e transdisciplinaridade no ensino. Interface - Comunicação, Saúde, Educação, São Paulo: UNESP, v. 2, n. 2, p. 173-182, 1998. Disponível em: https://repositorio.unesp.br/handle/11449/30363. Acesso em: 19 fev. 2019.

17. RIBEIRO, Raimunda da Cunha; MAGALHÃES, Antônio M. Política de responsabilidade social na Universidade: conceitos e desafios. Educação, Sociedade e Culturas, Porto, n. 42, p. 133-156, 2014. Disponível em: https:// www.fpce.up.pt/ciie/sites/default/files/ESC42_10RaimundaRibeiro.pdf. Acesso em: 12 abr. 2019.

18. SANTOS, Agnaldo dos. Cadernos de estudos avançados em design: sustentabilidade I. Belo Horizonte: EdUEMG, 2013. Disponível em: http://eduemg.uemg.br/arquivos/2009\%20-\%20CADERNOS\%20 DE \%20ESTUDOS\%20AVANCADOS\%20E M \% 20 DESI G N \% 20 - \% 20 SUSTENTABILIDADE\%20I\%20-\%20VOL.\%203.pdf. Acesso em: 13 dez. 2018.

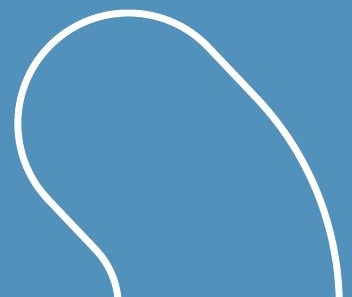


Projética, Londrina, v. 12, n. 2, p. 189-214, agosto 2021

19. SANTOS FILHO, José Camilo dos. Responsabilidade Social da Universidade. In: . COLÓQUIO DE GESTIÓN UNIVERSITÁRIA EN AMÉRICAS: RENDIMIENTOS ACADÉMICOS Y EFICACIA SOCIAL DE LA UNIVERSIDAD, 13., 2013, Florianópolis. Anais [...]. Florianópolis: UFSC, 2013. p. 1-19. Disponível em: https:// repositorio.ufsc.br/bitstream/handle/123456789/114752/2013060\%20 - \% 20 Responsabilidade \% 20 s o cia l \% 20 da \% 20 un iversidade. pdf?sequence=1\&isAllowed=y. Acesso em: 23 out. 2018.

20. SANTOS, Jacqueline Guimarães; SOUZA, Natália Mary Oliveira de. A influência da responsabilidade social empresarial no comprometimento dos colaboradores: uma compreensão à luz da teoria do comportamento planejado. In: ENCONTRO DE GESTÃO DE PESSOAS E RELAÇÕES DETRABALHO, 4., 2013, Brasília, DF. Anais [...]. Brasília, DF: ANPAD, 2013. Disponível em: http://www.anpad.org.br/admin/pdf/EnGPR188.pdf. Acesso em: 22 out. 2018.

21. SILVA, Inês Amaro da. Responsabilidade social universitária, qualidade e pertinência social: desafios à gestão. Diálogo, Canoas, n. 29, p. 9-28, 2015. Disponível em: https://revistas.unilasalle.edu.br/index.php/Dialogo/article/ view/2238-9024.15.1/pdf. Acesso em: 12 abr. 2019.

22. SOUZA, Paulo Fernando de Almeida. Sustentabilidade e responsabilidade social no design do produto: rumo à definição de indicadores. 2007. Tese (Doutorado em Design e Arquitetura) - Faculdade de Arquitetura e Urbanismo, Universidade de São Paulo, São Paulo, 2007. Disponível em: http://www.teses.usp.br/teses/disponiveis/16/16134/tde-20052010-154910/ pt-br.php. Acesso em: 02 mar. 2019.
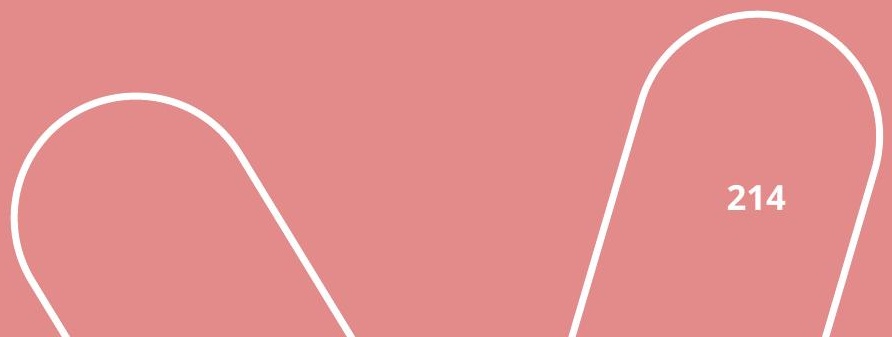